\title{
An Unusual Anatomic Variation of the Jugular Foramen with Doubled Posterior Condylar Canal
}

\author{
Una Variación Anatómica Inusual del Foramen Yugular con Canal Condilar Posterior Duplicado
}

\author{
Samet Kapakin
}

KAPAKIN, S. An unusual anatomic variation of the jugular foramen with doubled posterior condylar canal. Int. J. Morphol., 29(4):11861188, 2011.

SUMMARY: A case of unusual anatomical variation of the jugular foramen (JF) with doubled posterior condylar canal (PCC) is reported. According to the presence of bridging, the JF can be defined as Type I (one septation, two compartments) on the right side and Type IV (three septations, four compartments) on the left side. The dome of the jugular fossa is present on the right, absent on the left. The jugular foramen shows a canal-like structure with an external and an internal opening. The lengths of the longest and widest axes of the JFs are measured as $21.93 \times 16.56 \mathrm{~mm}$ on the right and $16.75 \times 15.14 \mathrm{~mm}$ on the left side. The right JF is larger. The PCC is doubled on the right side and there is only one on the left side. It is essential not only to know compartments per se but also to know the structures passing through the compartments, in order to achieve desired surgical outcomes and avoid complications.

KEY WORDS: Jugular foramen; Condylar canal; Anatomic variation.

\section{INTRODUCTION}

The jugular foramen $(\mathrm{JF})$ is one of the important foramina of the skull base. The ninth, tenth, and eleventh cranial nerves and the majority of the venous blood drained from the cranial cavity courses through this foramen (Athavale, 2010). It is difficult to conceptualize because it varies in size and shape in different crania, from side to side in the same cranium, and from its intracranial to extracranial end in the same foramen, and because of its complex irregular shape, its curved course, its formation by two bones, and the numerous nerves and venous channels that pass through it. The difficulties in exposing this foramen are created by its deep location and the surrounding structures, such as the carotid artery anteriorly, the facial nerve laterally, the hypoglossal nerve medially, and the vertebral artery inferiorly, all of which block access to the foramen and require careful management (Rhoton, 2000). Attempts at skull base surgery in the JF region have underscored the anatomic complexities of this region (Van Loveren et al., 1986; Kveton \& Cooper, 1988). Knowledge of complex anatomy and anatomic variability is, thus, crucial in determining surgical outcomes (Athavale).

The goal of this report is to delineate an unusual morphology and bridging pattern of the JFs and emphasize the importance of surgery of lesions involving this area.

\section{CASE REPORT}

During osteology demonstration classes for medical undergraduates, right and left jugular foramina were found to be different from each other in the dry skull of a 40-year-oldfemale.

According to the presence of bridging, we defined JF tip I on the right side (one septation, two compartments) and Type IV on the left side (three septations, four compartments). The dome of the jugular fossa was present on the right, absent on the left. We observed the canal-like structure of the JF with an external and an internal opening. The lengths of the longest and widest axis of the JFs were measured as $21.93 \times 16.56$ $\mathrm{mm}$ on the right and $16.75 \times 15.14 \mathrm{~mm}$ on the left side. The right JF was larger than the left one. The posterior condylar canal was doubled on the right side and there was only one on the left side of our case (Fig. 1).

\section{DISCUSSION}

Hovelaque in 1934 was probably the first to describe the compartmentation of the foramen (Rhoton \& Buza, 1975; Van Loveren et $a l$.). Since then, there has been a continuing debate over the number of compartments and the structures 


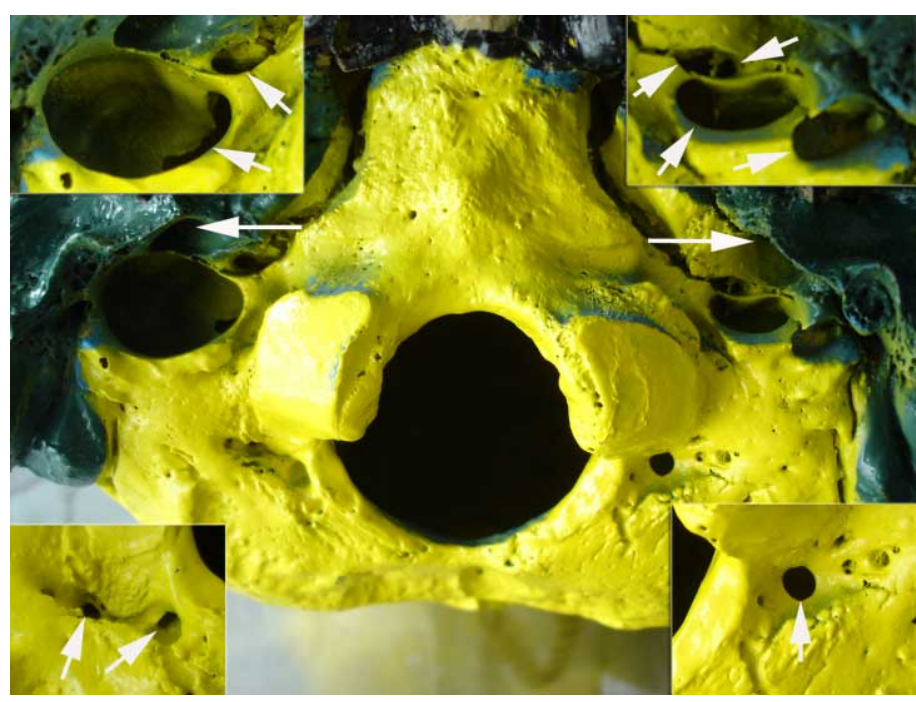

Fig. 1. The external aspect of jugular foramen bridging in a female skull. Various processes bridging the foramina are shown, dividing them into separate compartments. The upper right and upper left arrows indicate the exocranial openings of the compartments of the jugular foramina: two on the right side and four on the left side. The lower right and lower left arrows indicate the exocranial openings of the posterior condylar canals; two on the right side and one on the left side. The long arrows in the main picture indicate the external openings of the carotid canals.

passing through them. Several studies—osteologic (Hatiboglu \& Anil, 1992), microdissection (Tekdemir et al., 2001), and radiologic (Tekdemir et al., 1998) — have come forth with varied results. This has compounded the confusion further (Athavale).

There is also no agreement on the terminology about the compartmentalization of the JF (Tekdemir et al., 2001). Hovelacque has been credited with classifying the JF into two compartments as anteromedial and posterolateral (Van Loveren et al.). Classically, the smaller anteromedial neural compartment is called the pars nervosa, which contains the ninth cranial nerve, and the larger posterolateral vascular compartment is called pars vascularis, which contains the jugular bulb and the tenth and eleventh cranial nerves (Rhoton \& Buza, 1975). However, Shapiro (1972) also described a third compartment containing the inferior petrosal sinus, which was located at the most medial portion of the JF. Recently, Katsuta et al. (1997) redefined the compartments of the JF and classified the petrosal part, intrajugular part, and sigmoid part according to the structures which passed through the JF. The intrajugular or neural part through which the glossopharyngeal, vagus and accessory nerves run was located between the sigmoid and petrosal parts at the region of the intrajugular processes of the temporal and occipital bones. We hold that Katsuta et al.'s definitions of the JF compartments are more dependable and explanatory than previous ones (Tekdemir et al., 2001).

In our case, the right JF was divided into two compartments by the intrajugular process; the anterior and the posterior were consistent with Hovelacque, but the left one was an unusual variation as follows: the JF was completely divided into four compartments by a bony septum: the anteromedial, the anterolateral, the middle and the posterior. Unlike earlier cases, this case was defined as Type IV bridging, where respective processes failed to meet and, instead, atypical fusion of processes took place (e.g., the anterior occipital process meets the posterior petrous process), forming atypical compartments (Athavale). The petrosal part described by Katsuda et al. was divided into two compartments: the anteromedial containing the inferior petrosal sinus, and the anterolateral containing the ninth cranial nerve. The middle or intrajugular was located between the sigmoid and petrosal parts. The posterior or sigmoid part lay posterolaterally.

As far as jugular foramina are concerned, asymmetry is seen in two-thirds of cases, with the right JF reported as being larger (Idowu, 2004). The purpose of this asymmetry still remains unclear (Wysocki et al., 2006). The right JF was greater than the left in our case as well.

The differences in size of the right and the left jugular veins are reflected in the differences between the jugular foramina. It might be expected that the right foramen would usually be larger than the left, since the superior sagittal sinus is usually described as draining into the right transverse sinus (Hatiboglu \& Anil).

Berge \& Bergman (2001) found that the posterior condylar canal was doubled in six of the 144 patent foramina ( $4 \%$ ) and tripled in one case $(<1 \%)$. In our case, the posterior condylar canal (PCC) was doubled on the right side and there was only one on the left side.

Studies have reached different conclusions, probably for two reasons. First, the anatomy of the JF shows great variation from person to person. Second, dissection of the foramen is a destructive process in which the structures remaining cannot be related to the structures that have been removed (Rubinstein et al., 1995).

Different pathologic conditions involve the JF and may result in lower $\mathrm{CN}$ deficits (Ramina et al., 2005). Lower cranial nerve deficits leading to dysphagia, breathing difficulty, hoarseness, and pneumonia due to aspiration are potential dangerous problems (Mattos et al., 2004). Understanding the relationship of the compartments of the JF to the lower $\mathrm{CN}$ is essential if neural preservation is desired. 
The surgical anatomy of the JF and its contents is complex. Therefore, an excellent knowledge of its variations and the relationships between its neurovascular structures is critical when surgically approaching this complex area, in order to maximize the surgical outcome and decrease postoperative complications when treating the pathology of this region (Keles et al., 2009).
The factors playing a role in shaping the structure of the JF and the structures passing through the foramen may change; therefore, it is essential not only to know compartments per se but also to know the structures passing through the compartments, in order to achieve desired surgical outcomes and avoid complications.

KAPAKIN, S. Una variación anatómica inusual del foramen yugular con canal condilar posterior duplicado.Int. J. Morphol., 29(4):1186$1188,2011$.

RESUMEN: Ee reportado el caso de una inusual variación anatómica del foramen yugular (FY), con el canal condilar posterior duplicado (CCP). De acuerdo con la presencia de los puentes, el FY se puede definir como Tipo I (una tabicación, dos compartimientos) en el lado derecho y Tipo IV (tres tabiques, cuatro compartimientos) en el lado izquierdo. El domo de la fosa yugular está presente en el lado derecho, y ausente en el izquierdo. El foramen yugular mostró una estructura igual a un canal con una apertura externa y otra interna. Las longitudes de los ejes más largos y anchos de la FY fueron 21,93x16,56mm al lado derecho y 16,75x15,14mm al lado izquierdo. El FY derecho fue más grande. El CCP se observó duplicado en el lado derecho y único en el lado izquierdo. Es esencial no sólo conocer los compartimientos en sí, sino también las estructuras que pasan a través de los compartimientos con el fin de lograr los resultados deseados y evitar las complicaciones quirúrgicas.

PALABRAS CLAVE: Foramen yugular; Canal condilar; Variación anatómica.

\section{REFERENCES}

Athavale, S. A. Morphology and compartmentation of the jugular foramen in adult Indian skulls. Surg. Radiol. Anat., 32(5):447$53,2010$.

Berge, J. K. \& Bergman, R. A. Variations in size and in symmetry of foramina of the human skull. Clin. Anat., 14(6):406-13, 2001.

Hatibog `lu, M. T. \& Anil, A. Structural variations in the jugular foramen of the human skull. J. Anat., 180(1):191-6, 1992.

Idowu, O. E. The jugular foramen-a morphometric study. Folia Morphol., 63(4):419-22, 2004.

Katsuta, T.; Rhoton, A. L. Jr. \& Matsushima T. The jugular foramen: Microsurgical anatomy and operative techniques. Neurosurgery, 41(1):149-202, 1997.

Keles, B.; Semaan, M. T. \& Fayad, J. N. The medial wall of the jugular foramen: a temporal bone anatomic study. Otolaryngol. Head Neck Surg., 141(3):401-7, 2009.

Kveton, J. F. \& Cooper, M. H. Microsurgical anatomy of the jugular foramen region. Am. J. Otol., 9(2):109-12, 1998.

Mattos, J. P.; Ramina, R.; Borges, W.; Ghizoni, E.; Fernandes, Y. B.; Paschoal, J. R.; Honorato, D. C. \& Borges G. Intradural jugular foramen tumors. Arq. Neuropsiquiatr., 62(4):997-1003, 2004.

Ramina, R.; Maniglia, J. J.; Fernandes, Y. B.; Paschoal, J. R.; Pfeilsticker, L. N. \& Coelho Neto, M. Tumors of the jugular foramen: diagnosis and management. Neurosurgery, 57(1):5968,2005 .

Rhoton, A. L. Jugular foramen. Neurosurgery, 47(3):267-85, 2000.
Rhoton, A. L. Jr. \& Buza, R. Microsurgical anatomy of the jugular foramen. J. Neurosurg., 42(5):541-50, 1975.

Rubinstein, D.; Burton, B. S. \& Walker, A. L. The anatomy of the inferior petrosal sinus, glossopharyngeal nerve, vagus nerve, and accessory nerve in the jugular foramen. AJNR Am. J. Neuroradiol., 16(1):185-94, 1995.

Shapiro, R. Compartmentation of the jugular foramen. J. Neurosurg., 36(3):340-3, 1972.

Tekdemir, I.; Tuccar, E.; Aslan, A.; Elhan, A.; Deda, H.; Ciftci, E. \& Akyar, S. The jugular foramen-a comparative radioanatomic study. Surg. Neurol., 50(6):557-62, 1998.

Tekdemir, I.; Tuccar, E.; Aslan, A.; Elhan, A.; Ersoy, M. \& Deda H. Comprehensive microsurgical anatomy of the jugular foramen and review of terminology. J. Clin. Neurosci., 8(4):351-6, 2001.

Van Loveren, H. R.; Liu, S. S.; Pensak, M. L. \& Keller, J. T. Anatomy of the jugular foramen: The neurosurgical perspective. $O p$. Techn. Otolaryngol. Head Neck Surg., 7(2):90-4, 1996.

Wysocki, J.; Reymond, J.; Skarz yn’ski, H. \& Wróbel, B. The size of selected human skull foramina in relation to skull capacity. Folia Morphol., 65(4):301-8, 2006.

Correspondence to:

Samet Kapakin

Atatürk University

Faculty of Medicine

Department of Anatomy

Erzurum 25240

TURKEY

Received: 19-12-2010

Accepted: 28-06-2011

Email:sametkapakin@gmail.com 